\title{
Combustion Characteristics and Pollution Minimum Technology for VR (Vacuum Residue) Fired Boiler*
}

\author{
Toshimitsu ICHINOSE**, Koutaro FUJIMURA**, \\ Keiji TAKENO**, Toshiki MOTAI***, \\ Yoshihisa ARAKAWA*** and Hiroshi FUJII***
}

\begin{abstract}
An experimental study on the combustion of extra heavy oil has been performed using a cylindrical test furnace. Recently, light oil such as gasoline is almost exclusively demanded as liquid fuel made from petroleum. In order to produce light oil in a high yield, extra heavy oil, which is called as VR (Vacuum Residue), remains after refinement under reduced pressure. VR features extremely high viscosity, as well as high percentages of sulfur, nitrogen, heavy metals, and resident carbon in fuel. Regarding the use of VR as a fuel for actual commercial boilers, a number of serious problems must be overcome. These include high- and low-temperature corrosion of metal materials, and the need to meet environmental regulations calling for low $\mathrm{NO}_{x}$ and a low unburned carbon ratio in exhaust gas. In the present study, accordingly, a firing test has been conducted to accumulate the basic characteristics of VR combustion. From the test results, stable ignitability was ascertained, and both $\mathrm{NO}_{x}$ emission and the unburned carbon ratio in exhaust gas were found to be at the same level as for bituminous coal combustion. Also, the reactivity and the carbon structure of the sampled soot and char were chemically examined in detail, and the reaction rate with oxygen was formulated. Furthermore, numerical simulation of combustion in onedimensional furnace was conducted, and the calculated results were compared with the experimental data.
\end{abstract}

Key Words: Fossil Fuel Fired Power Generation, Liquid Fuel, Boiler, Combustion Product, Combustion

\section{Introduction}

As liquid fuel made from petroleum, light oil such as gasoline is exclusively demanded recently. Accordingly, the trend for heavy oil remaining after distillation to be used as the fuel for commercial boilers has been rising. In recent years, refinement of petroleum has been conducted under reduced pressure, and the oil remaining after this process becomes heavier. This extra heavy oil is called as VR (Vacuum Residue), and is characterized by high percentages of the resident carbon, sulfur, nitrogen, and heavy metals, as

* Received 13th July, 1997

** Nagasaki Research and Development Center, Mitsubishi Heavy Industries, Ltd., 5-717-1 Fukahorimachi, Nagasaki 851-0392, Japan

*** Boiler Engineering Department, Mitsubishi Heavy Industries, Ltd., 3-1 Minatomirai 3-chome, Nishi-ku, Yokohama 220-8401, Japan well as by viscosity that is much higher than that for asphalt which has been the typical heavy oil heretofore.

Since the oil crisis, dependence upon heavy oil as an important energy source has been proceeding, and our company has constructed commercial boilers for heavy oil such as asphalt at more than twenty locations ${ }^{(1),(2)}$. Although technology for the combustion of heavy oil has essentially been established, VR is more difficult to utilize in actual commercial boilers, due to its high viscosity and high percentages of resident carbon and metals, while environmental standards for pollutant emission become increasingly strict.

Generally, if the value of excess oxygen in exhaust gas is permitted to be high, the soot and char contained in exhaust gas can be reduced to some degree, while the conversion from $\mathrm{SO}_{2}$ to more corrosive $\mathrm{SO}_{3}$ promotes, as well as the combustion 
Table 1 Properties of VR(Vacuum Residue) and C-heavy oil

\begin{tabular}{|c|c|c|c|c|c|c|}
\hline 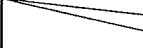 & & Fuel & VR $(1$ & acuum $\underline{R}$ & sidue) & Heavy Oil \\
\hline Item & $u$ & & A & B & C. & (Rank C) \\
\hline & $\begin{array}{c}\text { Calorific Value } \\
\text { (HHV) }\end{array}$ & $\mathrm{kcal} / \mathrm{kg}$ & 9950 & 9650 & 9720 & 10300 \\
\hline & $\begin{array}{c}\text { Specific Gravity } \\
\left(15 / 4^{\circ} \mathrm{C}\right)\end{array}$ & - & - & 1.081 & 1.092 & 0.95 \\
\hline $\begin{array}{c}\text { Proximate } \\
\text { Analysis }\end{array}$ & Viscosity & $\mathrm{cP}$ & $\begin{array}{c}5000 \\
\left(110^{\circ} \mathrm{C}\right)\end{array}$ & $\begin{array}{c}30000 \\
\left(110^{\circ} \mathrm{C}\right)\end{array}$ & $\begin{array}{c}10000 \\
\left(110^{\circ} \mathrm{C}\right)\end{array}$ & $\begin{array}{c}22 \\
\left(100^{\circ} \mathrm{C}\right)\end{array}$ \\
\hline & Ash & wt \% & 0.05 & 0.06 & 0.08 & 0.01 \\
\hline & Water & wt \% & $<0.01$ & $<0.01$ & 0.12 & $<0.1$ \\
\hline & Resident Carbon & wt $\%$ & 28 & 37.7 & 38 & 11 \\
\hline & $\mathrm{S}$ & wt \% & 5.56 & 4.8 & 3.04 & 3 \\
\hline & $\mathrm{N}$ & wt $\%$ & 0.47 & 0.43 & 0.92 & 0.2 \\
\hline Uitimate & V & $\mathrm{ppm}$ & 135 & 159 & 334 & 80 \\
\hline & $\mathrm{Ni}$ & ppm & 43.2 & 72 & 118 & 10 \\
\hline & $\mathrm{Na}$ & ppm & 66.1 & 26.6 & 55 & 30 \\
\hline
\end{tabular}

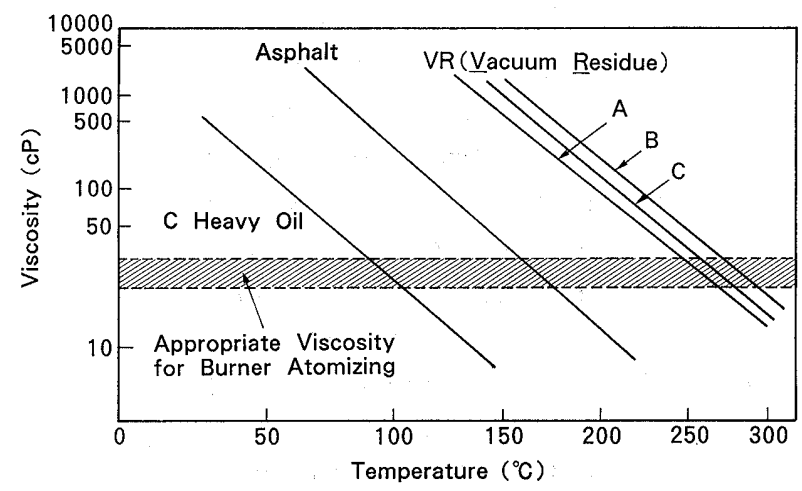

Fig. 1 Dependence of viscosity of heavy oil on temperature, represented in $\log \log$ (viscosity)-log (temperature) diagram

efficiency declines. In the present paper, therefore, VR firing tests have been conducted to accumulate the knowledge on combustion, and an appropriate distribution of combustion air was identified. Also, the structure of char in exhaust gas was chemically analyzed in detail and its reactivity is discussed.

\section{Features of VR}

Chemical analyses for four typical kinds of VR are shown in Table 1, with analyses of C-heavy oil and asphalt for references. Also, the dependence of viscosity on temperature is shown in Fig. 1, according to ASME procedures ${ }^{(3),(4)}$. The horizontal and vertical coordinates in Fig. 1 are calibrated as the logarithm of temperature and twice the logarithm of viscosity, respectively. When a high viscosity oil is measured using the capillary method, it is known that the viscosity-temperature curve can be well arranged in these special coordinates. Compared with C-heavy oil, which is the most popular fuel for oil-fired boilers, the features of VR are summarized as follows.

\section{(1) Very high viscosity}

Since VR is solid at room temperature, it must be heated in order to atomize with a burner. Even at $100^{\circ} \mathrm{C}$, which is the typical temperature for C-heavy oil atomization, the viscosity of VR is greater than $5000 \mathrm{cP}$. At $250-300^{\circ} \mathrm{C}$, viscosity becomes $20-30 \mathrm{cP}$, which is the ideal value for atomization with a twofluid-type burner assisted by steam or air.

\section{(2) High percentage of nitrogen in fuel}

The value of nitrogen contained in VR is generally $0.4-0.9 \mathrm{wt} \%$, which is approximately twice as large as that of C-heavy oil. Accordingly, low $\mathrm{NO}_{x}$ burners and de- $\mathrm{NO}_{x}$ equipment for exhaust gas should be provided to satisfy environmental regulations.

\section{(3) High percentage of sulfur in fuel}

The value of sulfur contained in VR is generally $3-6 \mathrm{wt} \%$, two to three times as high as that in $\mathrm{C}$ heavy oil. Generally, the conversion factor from sulfur in fuel to $\mathrm{SO}_{x}$ in exhaust gas is nearly $100 \%$. Therefore, chemical compounds such as magnesium should be provided to prevent the corrosion of metals exposed to high-temperatures, such as burner ports (due to light metal-sulfur compounds). Further, to prevent low-temperature corrosion of metals (due to $\mathrm{SO}_{3}$ produced from the reaction of $\mathrm{SO}_{2}$ with water) such as the rotating metal drum in the air preheating equipment where heat is exchanged between exhaust gas and the combustion air supplied to the burner, the temperature level of metal surface in the exhaust gas line should be controlled so as not to condense water.

\section{(4) High percentage of resident carbon}

The value of resident carbon in VR is $20-40$ wt\%, two to four times as high as that in C-heavy oil. Here, the percentage of resident carbon is defined as the residual weight of carbon after keeping the fuel at $850^{\circ} \mathrm{C}$ in inert gas, and this index shows the nature of carbon polymerization when fuel is heated. The high 
value for VR means that the carbon in VR is longchained. Generally, when the percentage of resident carbon in fuel increases, dust in exhaust gas tends to increase. Accordingly, the most important problem to overcome for the VR firing is to maintain a high combustion efficiency (low unburned carbon ratio), and this is deeply related to low $\mathrm{NO}_{x}$ and low $\mathrm{SO}_{3}$ technologies. This point is discussed later in more detail.

\section{Experimental Apparatus and Procedure}

For the VR firing test, the cylindrical furnace shown in Fig. 2 was used, with an inner diameter of $2.2 \mathrm{~m}$ and an inner length of $7.5 \mathrm{~m}$. The inner wall is coated with fireproof ceramics $10 \mathrm{~cm}$ thick, and the outer wall is surrounded by a water jacket. The system flow of the experimental apparatus is shown in Fig. 3.

Solid VR (VR-A in Table 1) was first crushed with a hammer crusher and melted in the fuel tank, the temperature of which was maintained at $250-300^{\circ} \mathrm{C}$

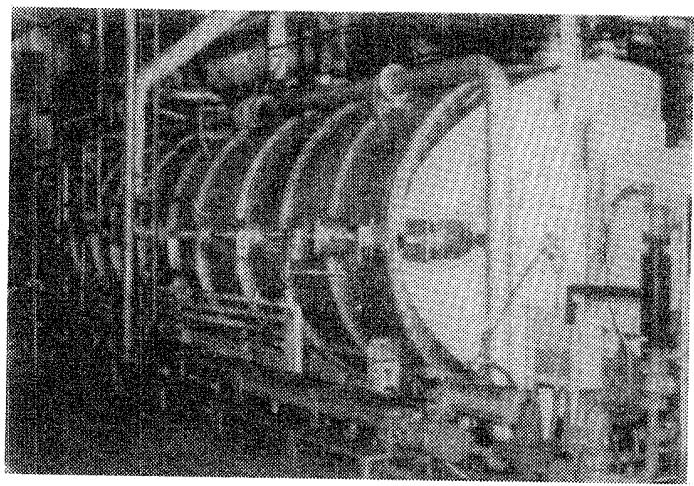

Fig. 2 Photograph of the test furnace(inner diameter: $2.2 \mathrm{~m}$, inner length : $7.5 \mathrm{~m}$ )

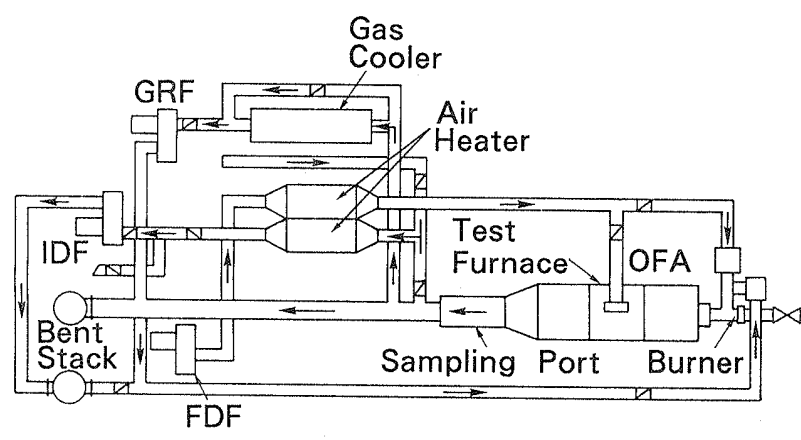

FDF by an electric heater. Double-annular tubes were used for all the VR piping with steam running through the gap between the inner and outer tubes. Prior to VR firing, C-heavy oil was supplied and the experimental apparatus was preheated. The exhaust gas sampled from the sampling port was analyzed using gaschromatography and the particles contained in exhaust gas were collected in a cylindrical filter.

\section{Soot and Char Contained in Exhaust Gas}

\section{1 Reactivity of resident carbon}

A typical photograph of particles sampled from exhaust gas is shown in Fig. 4. It is found that the sampled particles consist of a mixture of two kinds of particles; one is relatively large $(20-50 \mu \mathrm{m})$ with a rigid surface, and the other is relatively small (1-10 $\mu \mathrm{m})$ with a smooth surface. The large particles are considered to have originated in the resident carbon, because of its rigid surface, while the small are thought to be the soot produced in the gas phase through hydrocarbon polymerizing. These large

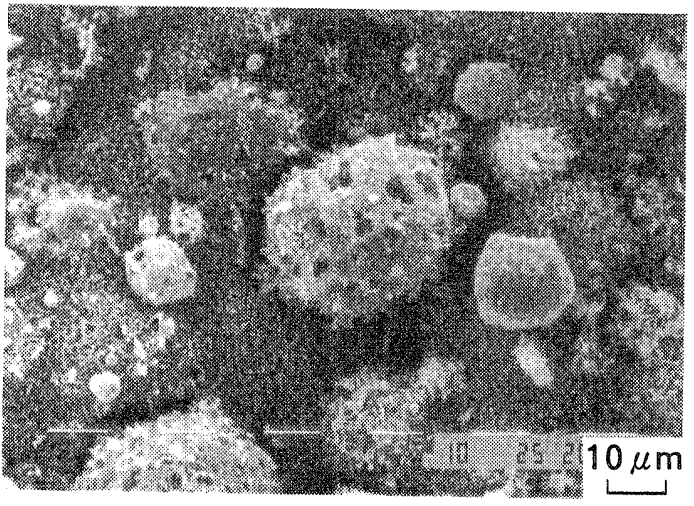

Fig. 4 Photograph of soot sampled from exhaust gas of VR (Vacuum Residue) firing

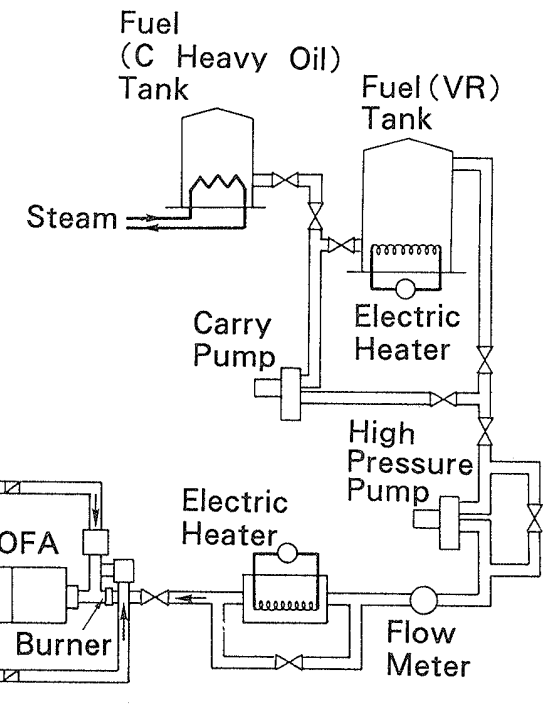

Fig. 3 System flow of experimental apparatus for VR (Vacuum Residue) firing test 
particles of unburned carbon are frequently referred to as cenosfur.

The reactivity of sampled particles was examined using a thermo-gravimetric analyzer. The change of weight when the temperature of sample was programmed to increase ( $T-G$ curve), is shown in Fig. 5. The rate of temperature increase was set at $10 \mathrm{deg} / \mathrm{min}$ somewhat low, in order to realize the reaction to be controlled by the reaction between particle surface and gas, but by the diffusion of gas adjacent to particle surface. The mechanism of oxidation reaction at the particle surface should be complex ${ }^{(5)}$, but attempts were made to correlate the reaction rate with the Arrehenius form of the simple first-order expression :

$$
-d X / d t=A_{a} P_{o_{2}}^{n}(1-X) \exp \left(-E_{a} / R T\right)
$$

where $X, A_{a}, E_{a}, P_{o_{2}}$, and $T$ represent the reaction ratio at time $t$, the apparent frequency factor, the activation energy, the oxidant partial pressure, and the particle temperature, respectively. The $T-G$ curve was converted to the Arrehenius expression using the following equation ${ }^{(6)}$ :

$$
\begin{aligned}
& \log \left\{-\frac{\log (1-X)}{2.303 T^{2}}\right\} \\
& =\log \frac{A_{a} R}{f E_{a}}\left(1-\frac{2 R T}{E_{a}}\right)-\frac{E_{a}}{2.303 R T}
\end{aligned}
$$

where, $f$ represents the rate of temperature increase in $\mathrm{T}-\mathrm{G}$ measurement, and the power $n$ of oxidant partial pressure is assumed to be 1.0.

Furthermore, particle structure was examined by means of X-ray diffraction pattern, and the typical chart measured is shown in Fig. 6. The absence of sharp peaks indicates that the particle has a random structure of carbon. A broad peak can be seen around $2 \theta=27 \mathrm{deg}$, which corresponds to the 002 diffraction surface of carbon as defined in the Miller index. The

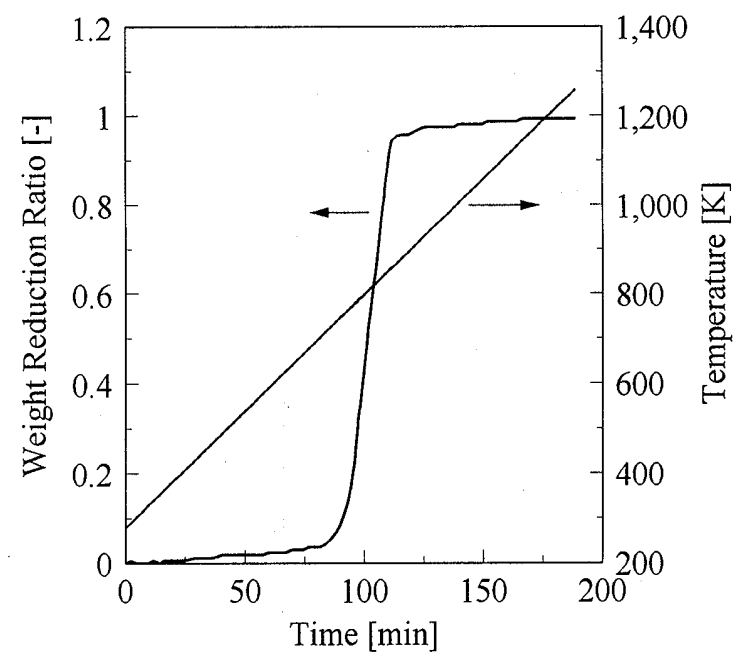

Fig. 5 Representative chart of results generated by thermo-gravimetric analyzer ( $\mathrm{T}-\mathrm{G}$ curve) for the soot of VR (Vacuum Residue) firing (oxygen : 5 vol\%) average diameter $\left(L_{c}\right)$ of crystallized carbon can be estimated from Fig. $6^{(7)}$.

The derived values of $A_{a}, E_{a}$, and $L_{c}$ are summarized in Table 2, compared with the values for typical bituminous coal char that was devolatilized during three seconds in nitrogen at $1200^{\circ} \mathrm{C}$. From Table 2, the value of $E_{a}$ for VR char is found to be about $10 \%$ greater than that for coal char. This means that, for VR combustion, the dependence of the reaction rate on temperature is more significant and that the temperature should be increased in order to reduce the unburned carbon, while $A_{a}$, which is the proportional coefficient of reaction rate, is approximately one-half of that for coal char. Furthermore, the value of $L_{c}$ for VR char is larger than that for coal char and the crystallization of carbon proceeds to a greater extent than coal char. These results imply that the reactivity of VR char tends to be lower than that for bituminous coal char.

\subsection{Numerical simulation of one-dimensional furnace}

The computer program used in the study was composed by expanding the combustion model for single particle ${ }^{(8),(9)}$, and the reaction rate of particle with oxygen was given by the derived equation in Arrehenius form. In the modeling of VR combustion, the weight percentage of resident carbon contained in VR was assumed to change to the char shown in Table 2 after the combustion of vaporized

Table 2 Characteristic values for the soot of VR and the char of bituminous coal, representative of reactivity and carbon crystallization

\begin{tabular}{|l|c|c|c|}
\hline \multicolumn{1}{|c|}{ Sample } & $\begin{array}{c}\mathrm{E}_{\mathrm{a}} / \mathrm{R} \\
\text { (Activation energy) }\end{array}$ & $\begin{array}{c}\mathrm{Aa} \\
\text { (Pre-exponential factor) }\end{array}$ & $\begin{array}{c}\text { Crystal diameter of } \\
002 \text { surface carbon }\end{array}$ \\
\hline $\begin{array}{l}\text { VR (vacuum } \\
\text { residue) char }\end{array}$ & $16350 \mathrm{~K}$ & $845 \mathrm{~s}^{-1} \mathrm{~atm}^{-1}$ & $28.8 \AA$ \\
\hline $\begin{array}{l}\text { Bituminous } \\
\text { coal char }\end{array}$ & $14950 \mathrm{~K}$ & $1526 \mathrm{~s}^{-1} \mathrm{~atm}^{-1}$ & $15.9 \AA$ \\
\hline
\end{tabular}

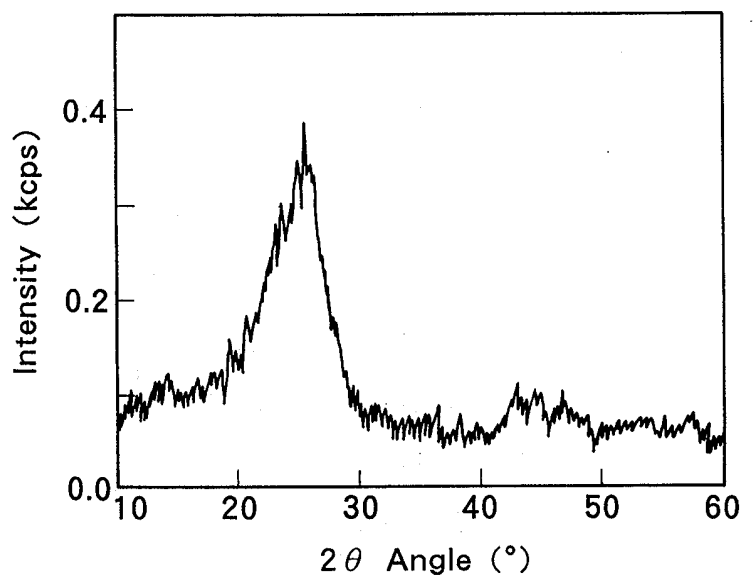

Fig. $6 \mathrm{XRD}(\mathrm{X}$-Ray Diffractometer) pattern for the soot of $\operatorname{VR}$ (Vacuum Residue) firing 
components. About the modeling of droplet vaporization and the coal combustion, refer to the Refs. (5), (8), and (9).

VR droplets atomized from a burner react along an one-dimensional gas stream ( $x$-coordinate), the temperature, composition, and velocity of which are determined from the mass and energy balances that hold true within each calculating cell (Fig. 7). In this simulation, the mean value of oxygen concentration at the cross section of flame was used as the value of oxygen concentration in each calculating cell, and the diffusion pattern along $x$-coordinate, which depends on the burner type and the angle or velocity of secondary combustion air, was assumed according to the empirical equation derived from accumulated data.

\section{3 Comparison between firing test and calcu- lated results}

In Fig. 8, the relationship between unburned carbon and excess oxygen in exhaust gas is shown for VR and a typical bituminous coal, where symbols and solid lines represent the experimental and calculated results, respectively. The proximate analysis of coal calculated here is as follows : water ; 7.7, carbon ; 57.6 ,

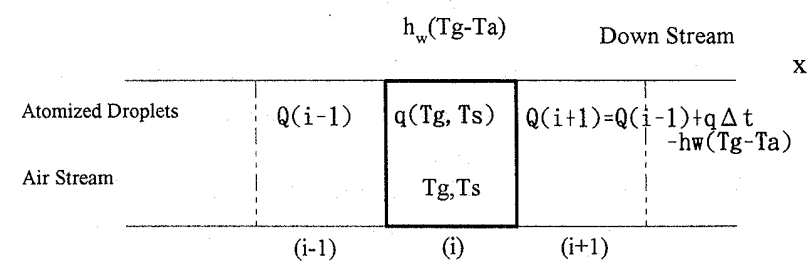

Fig. 7 Heat balance between control volumes (calculating meshes) in the one-dimensional furnace

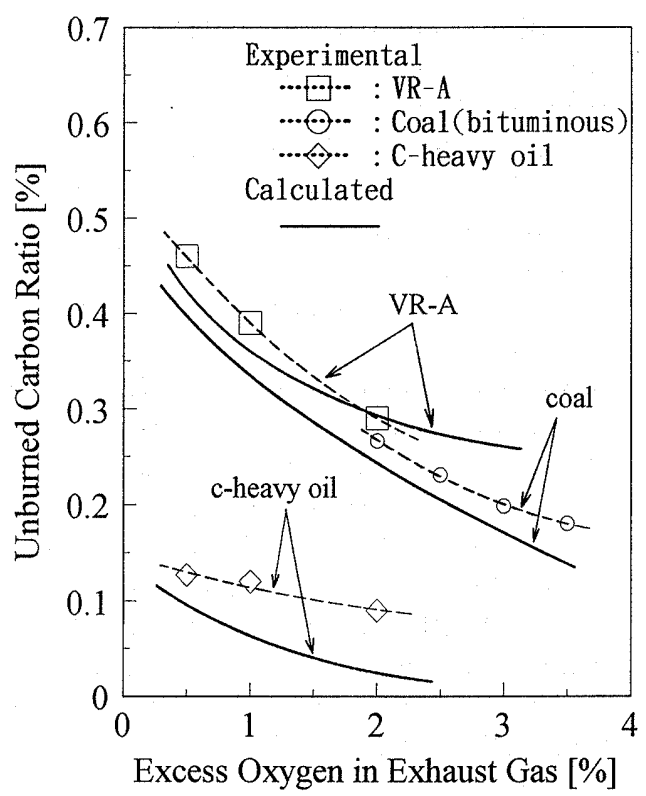

Fig. 8 Experimental and calculated results of the dependence of the unburned carbon ratio on excess oxygen concentration in exhaust gas volatile matter; 26.5 , ash; $8.2 \mathrm{wt} \%$, and calorific value ; $6370 \mathrm{kcal} / \mathrm{kg}$. In the calculation, for the distribution of particle diameter just atomized, measured atomization data were used as the initial condition.

For VR firing, when the values of excess oxygen are $0.5,1.0$, and $2.0 \%$, the unburned carbon ratios are $0.46,0.39$, and $0.29 \%$, respectively. These levels are approximately two to three times as large as those for $\mathrm{C}$-heavy oil, and a little higher than those for bituminous coal. When excess oxygen is greater than $2 \%$, the gradient of the curve for VR tends to become flatter than that of coal, while the gradient for the experimental data of VR shown with dotted line in Fig. 8 is steeper than that of calculated. Since the reaction data of carbon were obtained using the unburned carbon sampled from exhaust gas, this carbon should have a decreased reactivity due to the influence of carbon crystallization shown in Fig. 6 and Table 2. Compared the experimental results with the calculated, the structure of carbon must be changing with the reactivity of oxidization decreasing during the combustion process.

Since VR contains a high percentage of sulfur, excess oxygen should be reduced as much as possible, in order to prevent low-temperature corrosion due to $\mathrm{SO}_{3}$. It could be found that the unburned carbon ratio for VR is at almost the same level as with coal firing when low-excess oxygen operation is adopted.

\section{NO $x$ Emission from VR Combustion}

The relationships between excess oxygen and $\mathrm{NO}_{x}$ emission, and between OFA (Overfire Air) distribution and $\mathrm{NO}_{x}$ emission are shown in Figs. $9(\mathrm{a})$ and 9 (b), respectively. Here, OFA was introduced $5 \mathrm{~m}$ downstream from the burner port. With the increase of excess oxygen or the decrease of OFA distribution, $\mathrm{NO}_{x}$ emission in exhaust gas increases, and the absolute level of $\mathrm{NO}_{x}$ emission for $\mathrm{VR}$ is $15-25 \%$ greater than $\mathrm{C}$-heavy oil, while the weight percentage of nitrogen in fuel differs by more than two times.

Fig. 9(c) shows the relationship between nitrogen weight percentage and $\mathrm{NO}_{x}$ emission for various fuels. Since these experiments were conducted using the same experimental apparatus and the temperature distribution in the furnace was almost the same, the $\mathrm{NO}_{x}$ emission level obtained by extrapolating the nitrogen percentage in fuel toward zero represents the level of thermal $\mathrm{NO}_{x}$ (produced from the oxidation of nitrogen in combustion air). The gradient of curve $(0.3-0.4)$ in Fig. 9 ( c ) may represent the conversion factor from nitrogen in fuel to $\mathrm{NO}_{x}$. Since the experimental results for VR tend to be plotted a little under the correlation line in Fig. 9( c), the conversion ratio for VR appears to be lower than that for coal. 
(a)

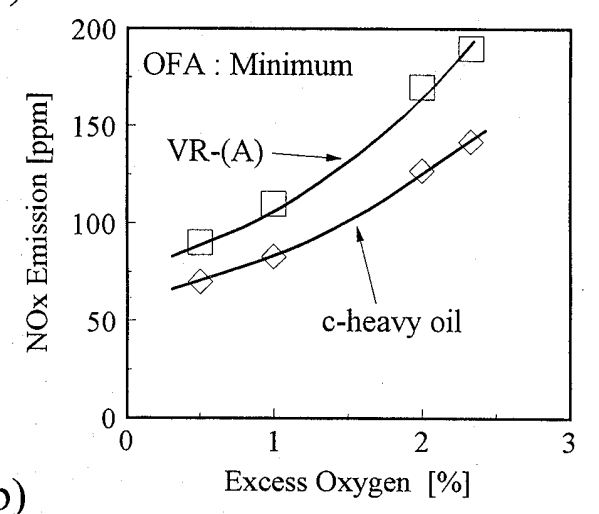

(b)

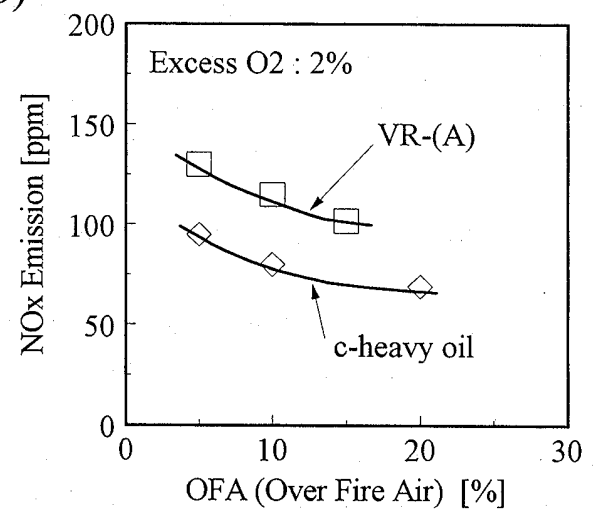

(c)

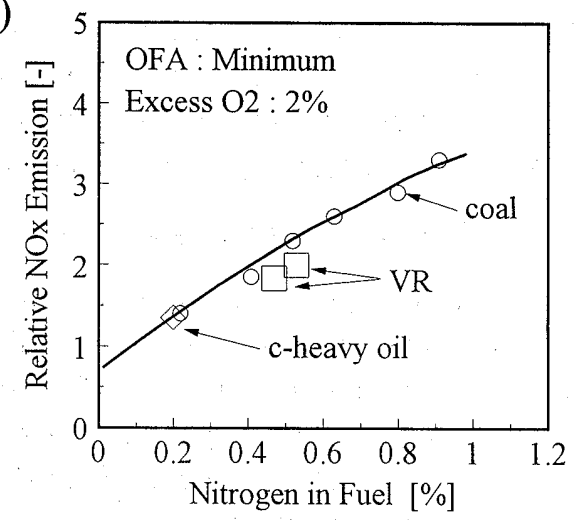

Fig. 9 Characteristics of $\mathrm{NO}_{x}$ emission in exhaust gas of VR (Vacuum Residue) firing test (absolute $\mathrm{NO}_{x}$ values are converted to values for $4 \%$ excess oxygen)

\section{Summary}

In the present study, firing tests for VR(Vacuum Residue) have been conducted using a cylindrical test furnace and the following results were obtained.

1) Since the viscosity of VR is extremely high, the temperature should be increased in order to atomize with a burner. At $250-300^{\circ} \mathrm{C}$, viscosity becomes $20-$ $30 \mathrm{cP}$, which is the ideal value for atomization with a two-fluid-type burner.
2) When the values of excess oxygen in exhaust gas were $0.5,1.0$, and $2.0 \%$, the unburned carbon ratios were $0.46,0.39$, and $0.29 \%$, respectively. These values were a little higher than those for typical bituminous coal.

3) The $\mathrm{NO}_{x}$ emission in exhaust gas was approximately $110 \mathrm{ppm}$, with $4 \%$ excess oxygen and $5 \%$ OFA (Overfire Air). Although the weight ratio of nitrogen in VR was about twice as large as that for C-heavy oil, the $\mathrm{NO}_{x}$ emission level was only $15-20 \%$ higher. The form of nitrogen bonding among the carbon chain of fuel will bring about the difference in fuel- $\mathrm{N}$ to $\mathrm{NO}_{x}$ conversion ratio. This is an important subject to be clarified in the next step.

4) The reactivity and carbon structure of dust sampled from exhaust gas were chemically examined, and the rate of reaction with oxygen was derived as Arrehenius expression. One-dimensional numerical simulation of VR combustion was conducted applying the derived equation of reaction rate, and the experimental and calculated results for the relationship between excess oxygen and unburned carbon ratio were found to agree fairly well.

\section{References.}

(1) Oguri, M., Tokuda, K. and Nakashima, F., Mitsubishi Heavy Industries, Technical Review, Vol. 26, No. 1(1989), p. 77.

(2) Sakai, M., Tokuda, K. and Nakashima, F., Mitsubishi Heavy Industries, Technical Review, Vol. 23, No. 5(1986), p. 69.

(3) ASME Designation: D2170, Standard Test Method for Kinetic Viscosity of Asphalts(1985, reapproved 1990).

(4) ASME Designation: D341(1989), Standard Viscosity-Temperature Charts for Liquid Petroleum Products, (1989).

(5) Niksa, S., Heyd, L.E., Russel, W.B. and Saville, D.A., Twentieth Symposium (International) on Combustion, The Combustion Institute, Pittsburgh (1985), p. 1445.

(6) Coats, A.W. and Redfern, J.P., Nature, Vol. 201, No. 68(1964), p. 27.

(7) Kothandaraman, G. and Simons, G.A., Twentieth Symposium(International) on Combustion, The Combustion Institute(1984), p. 1523.

(8) Kaneko, S., Suganuma, H., Kobayashi, Y., Tokuda, K. and Takeno, K., Proceedings of the Nineteenth International Technical Conference on Coal Utilization and Fuel Systems, (1994), p. 874.

(9) Tákeno, K., Tokuda, K., Ichinose, T. and Kaneko, S., Twenty-Sixth Symposium (International) on Combustion, The Combustion Institute, (1996), p. 3223. 